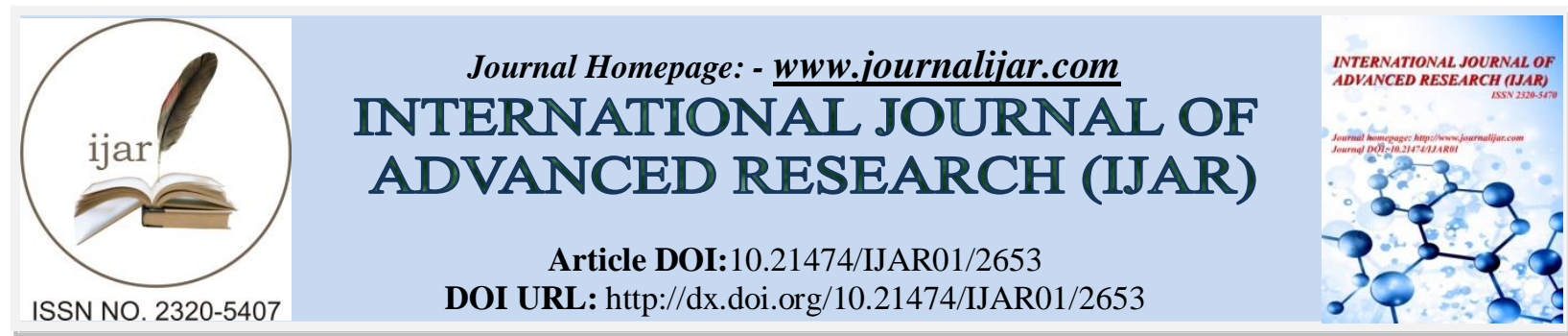

RESEARCH ARTICLE

\title{
A PRAGMATIC REVIEW OF LOW BACK ACHE AND ITS PRACTICAL APPROACH.
}

Dr. Vijay Kumar S. Shabadi M.Ch ${ }^{1}$, Dr. Satish Rudrappa M.Ch, FASS ${ }^{2}$ and Dr. J. Chandramohan MS ${ }^{3}$.

1. Associate Consultant in Institute Of Neurosciences, Sakra World Hospital, Bangalore,India.

2. Consultant and Head of Spine Neurosurgery, Sakra World Hospital, Bangalore,India.

3. Associate Professor of Surgery, Basaweshwara Medical College and Research Center, Chitradurga,India.

\section{Manuscript Info}

..........................

Manuscript History

Received: 30 October 2016

Final Accepted: 29 November 2016

Published: December 2016

\section{Abstract}

Background: Low back ache is a common problem encountered in day today practice. These cases are often handled by general practioners, general surgeons, orthopedicians, neuro-physicians and neurosurgeons. It is such a lingering problem that the patients often land up in window shopping of doctors and lands up getting treated inadequately and haphazardly. It also puts the patient in a vicious cycle of depression if not treated properly.Often the methodical approach of treating back pain is neglected by many treating physicians. A systematic and brief review of the subject is necessary to understand the practical approaches towards this common but yet enigmatic problem.

Aims And Objectives: To analyze different causes and presentations of low back ache. To draw a systematic approach towards the management of these cases and formulate a simple practical guide for the medical practioners.

Conclusion: Low back ache is a common problem of 21st century. Not all cases need surgery. Choosing properly indicated patients with good co-relation of clinical and radiological findings adds to good results in well trained hands. Surgery is an alternative only when conservative treatment fails to this common pathology

Copy Right, IJAR, 2016,. All rights reserved.

\section{Introduction:-}

Evolution of human beings from quadruped to biped posture resulted in "S" shaped curvature of spine so that back muscles have tension band effect keeping the spine erect so that the entire weight of body and gravity is not on the spine but shared by the muscles. Hence if the curvature is not maintained, the stress and strain is entirely on intervertebral discs leading to degenerative changes.Low back pain (LBP) is a major health and socioeconomic problem in modern society. In modern day society 1 in 3 persons are often affected by this common problem. 


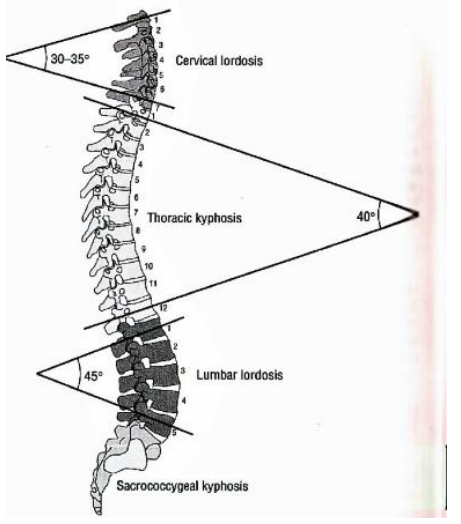

Low back ache-Common causes of low back ache:-

1. Back muscle spasm

2. Acute disc herniation

3. Facet arthropathy

4. Lumbar degenerative stenosis and listhesis

Back muscle spasm:Clinically history clinches the diagnosis and on examination most often can feel the spasm of back muscles and patients will have no radiculopathy or deficits.

\section{CAUSES:}

- Sudden strenuous activity

- Sports related injuries

- Prolonged wrong posture

- Co-existing acute disc herniation or facet arthritis

\section{Treatment of acute back spasm consists of:}

- Simple NSAIDS

- Muscle relaxants if prolonged pain

- Ultrasound and IFT therapy

- In case of severe spasm complete bed rest on firm flat surface for not more than 2 days

Low back ache with lumbar disc herniation:

\begin{tabular}{|c|}
\hline ssical manifestations of Lateral \\
\hline
\end{tabular}

\section{Classic manifestations of Central disc herniation:}

- Back ache more prominent than leg pain

- Bilateral leg pain rarely extending beyond knee joint

- Bilateral leg numbness

- Sphincter involvement

- Straight leg raising test normal

- Back pain more on lifting objects than on walking
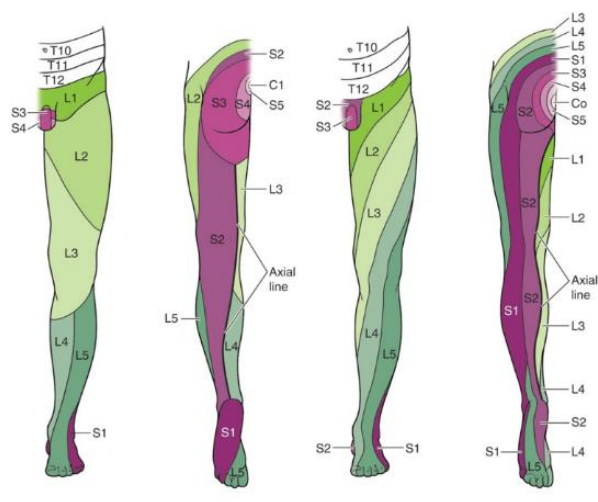

(D) Posterior view 
After initial evaluation and during first time presentations patients are usually prescribed conservative treatment:

Absolute bed rest for maximum 3 days

NSAIDS and muscle relaxants

Physiotherapy:Yoga and back excercises

Ultrasound and IFT therapy

Indications for surgical intervention- Microlumbar discectomy:-

Failed conservative management

Neurological deterioration and sphincter involvement

New onset neurological deficits

Obese young patients with severe central disc herniation

Management protocol of low bak pain dureto lumbar disc herniation:

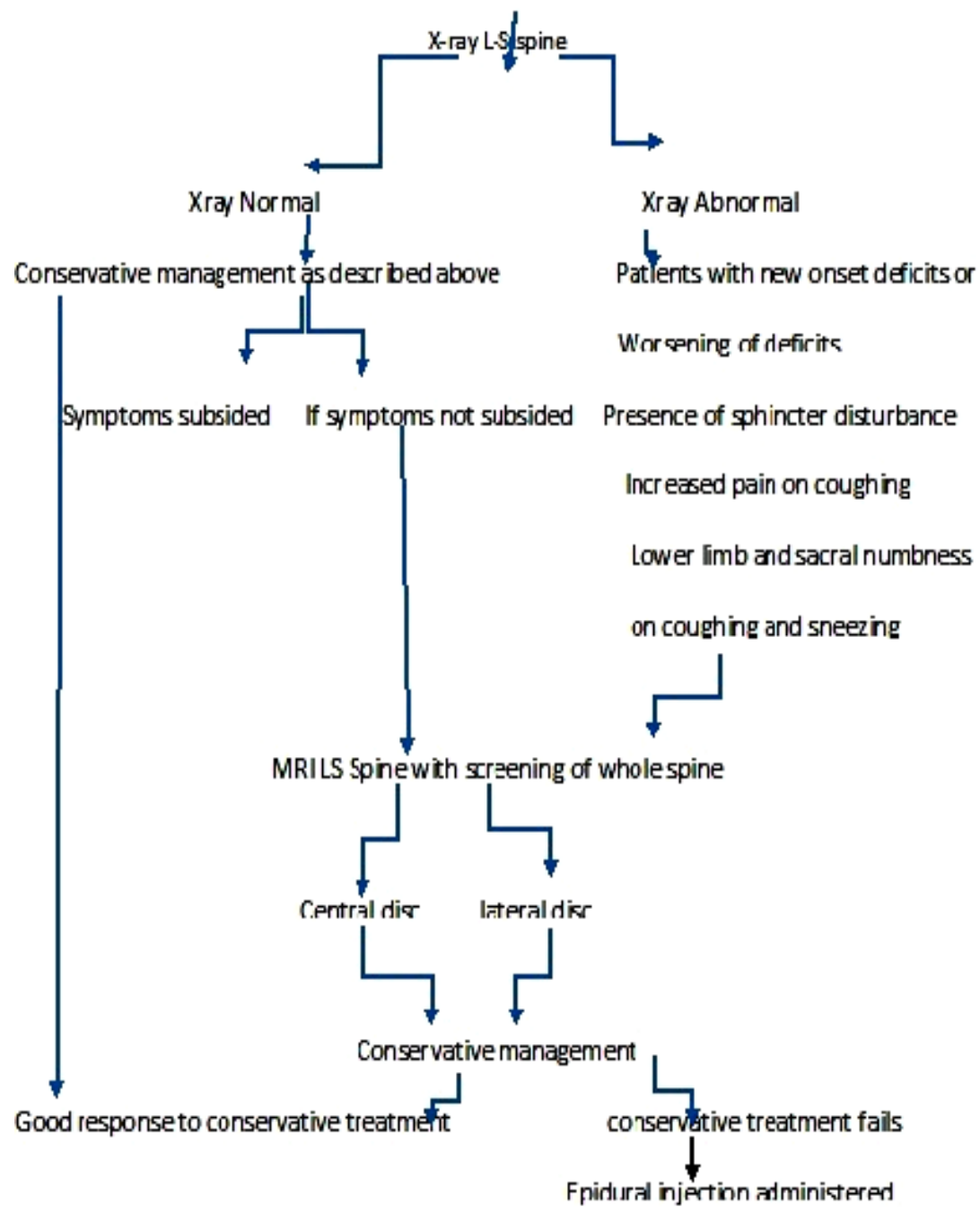



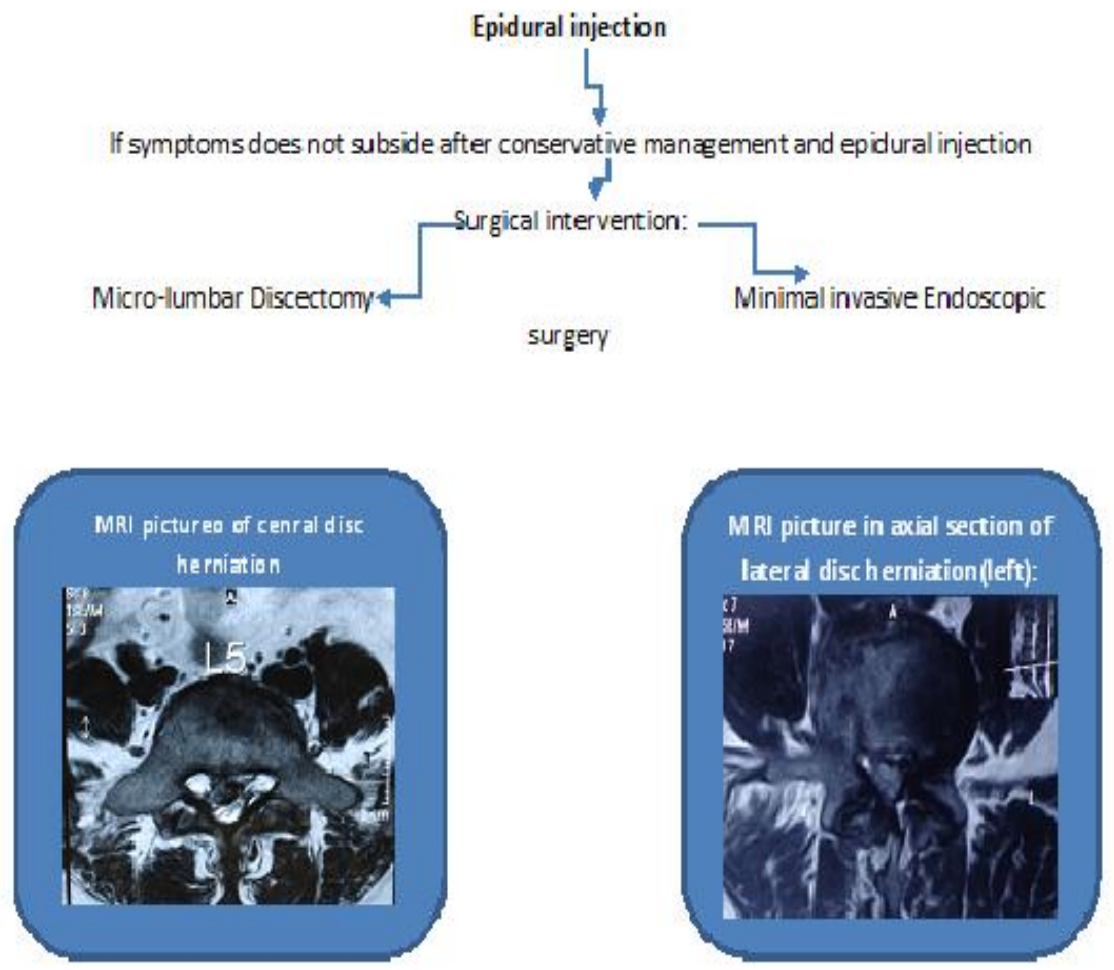

Low back ache due to facet arthropathy:-

\begin{tabular}{l|} 
Incidence: $60 \%$ of low back ache \\
Common in elder population \\
Worsens with extension or rotation movement of spine \\
Pain rarely radiates below knee joint \\
Severe cases leads to nerve entrapment leading to: weakness, numbness, radicular pain \\
Tender joints on examination \\
Restriction of back movements
\end{tabular}

MRI VIEW OF LUMBAR CANAL STENOSIS:

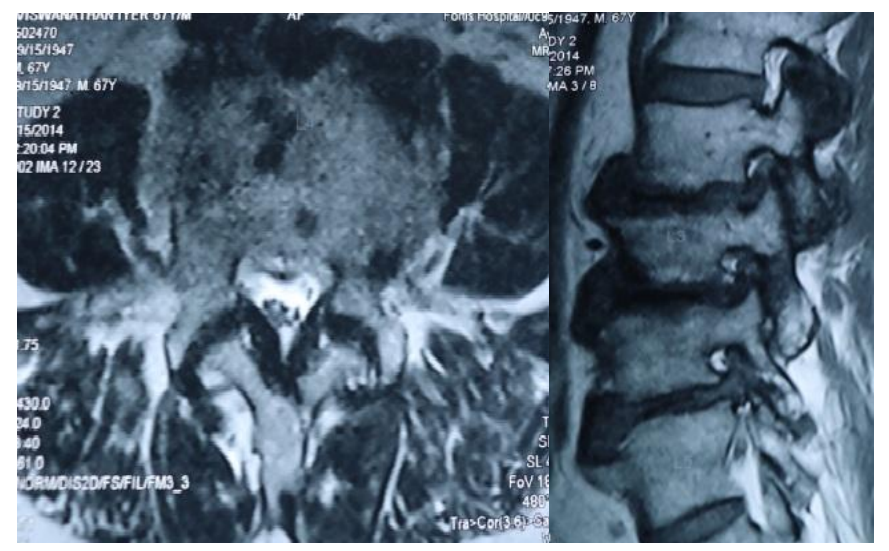




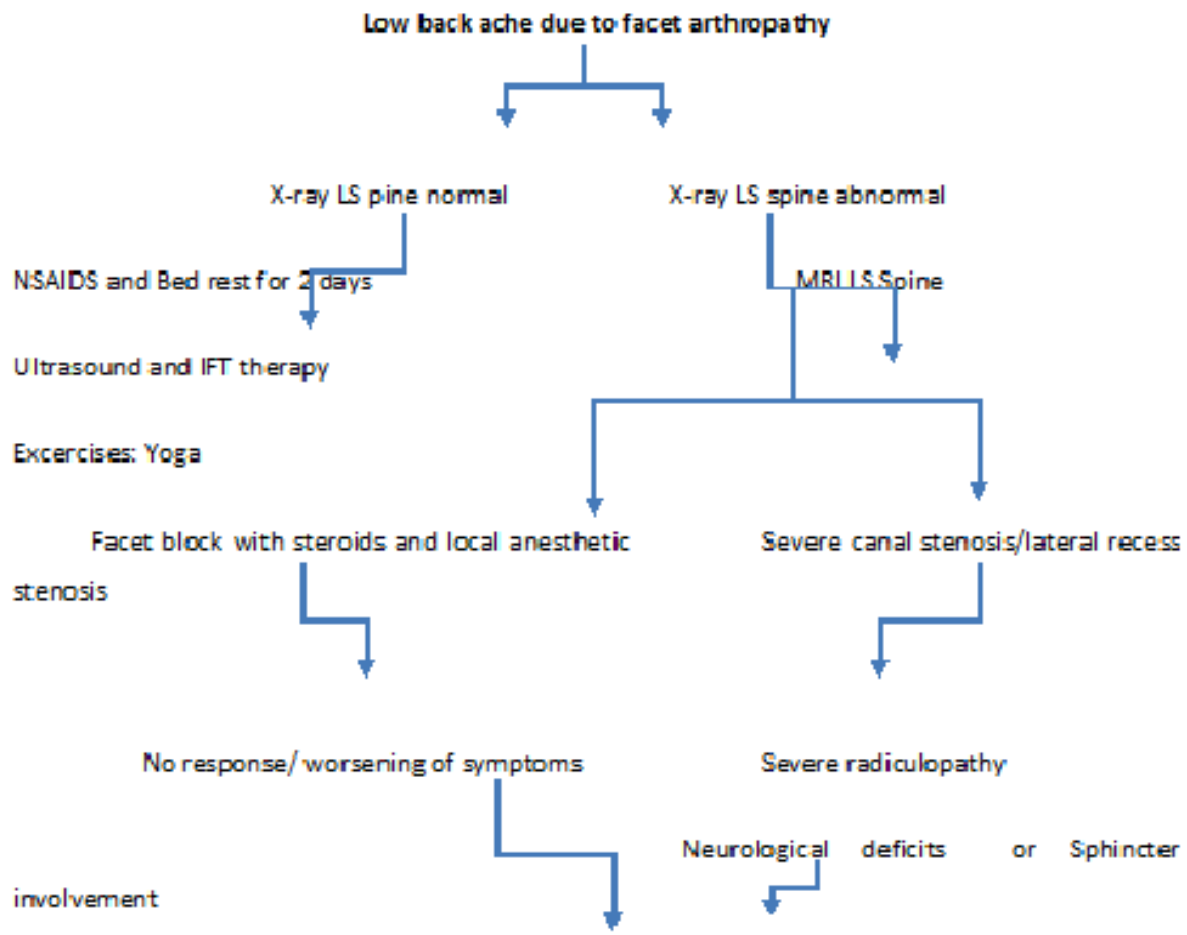

Surgical intervention: Internal decompression

\section{Lumbar listhesis and canal stenosis - degerativespondylolisthesis:-}

Usually these patients have chronic degenerative disc which over a period of time due to abnormal posture leads to facet joint arthropathy leading to defect in pars which is termed as spondylolysis. This progresses as there is ongoing motion with instability leading to spondylolisthesis and compromise of spinal canal as well as lateral recess leading to canal stenosis.

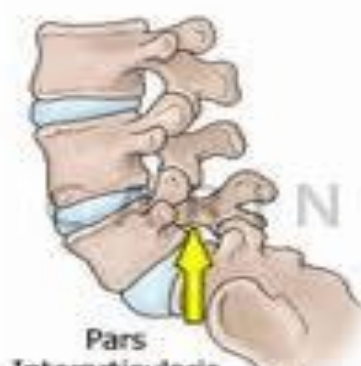

Interarticularis

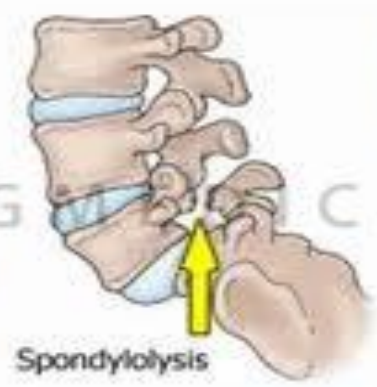

Spondylotysis

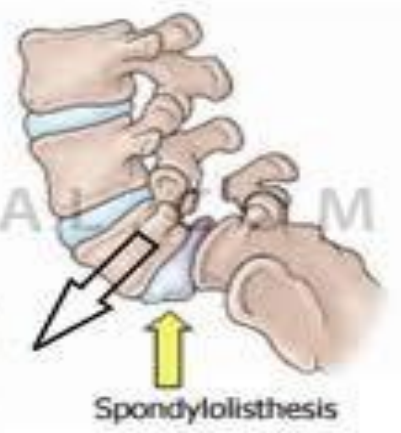


Xray and MRI of L4-L5 listhesis:

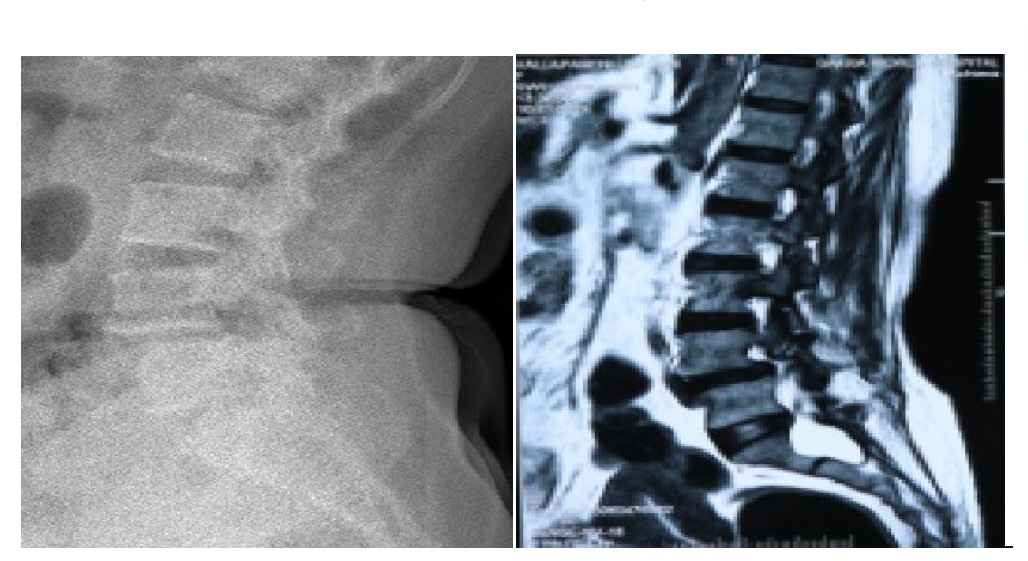

Grades of spondylolisthesis

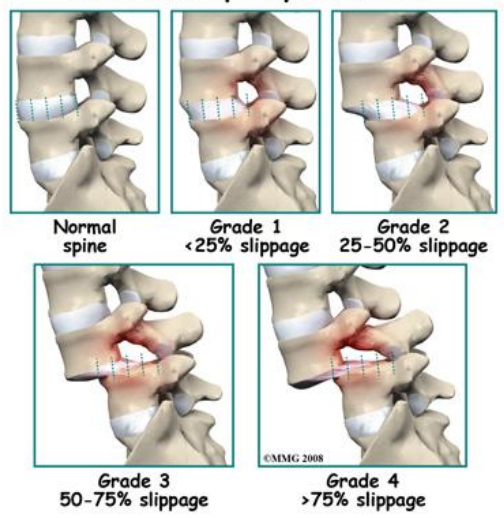

- More common in elderly females

- Most common level is L4-L5 level

- Associated with severe facet joint disease

- Subluxation causes narrowing of spinal canal

- Hypertropic joints encroach on neural foramina causing compression of nerve root

Classical features of lumbar canal stenosis:-

- More common in elderly patients

- Pain is not present on standing but worsening on moving for some distance

- Pain is associated with numbness of bilateral lower limbs

- Pain gets relieved on bending forward or stooping forward

- Severe stenosis may lead to neurological deficits and sphincter involvement

MRI picture of Lumbar canal stenosis:-

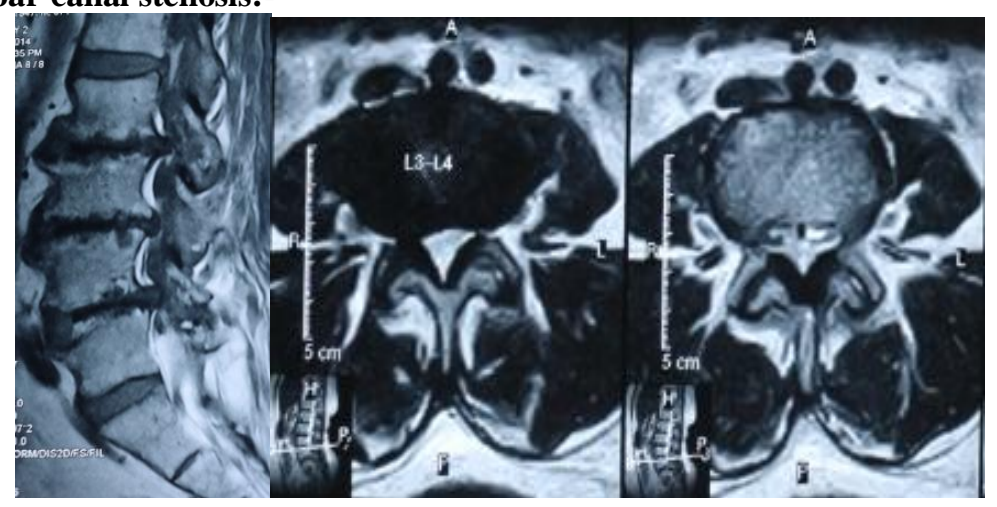

Management of low back pain with spondylolisthesis:-

Non operative management is the mainstay of the management

Bed rest for 2 days with NSAIDS and muscle relaxants

Aerobic excercises/Yoga

Weight reduction/careful management of osteoporosis

Indications for surgery:-

- If patient does not respond to non-operative measures

- Severe radiculopathy

- Patient has degenerative scoliosis

- Neurological deficits: weakness, numbness sphincter involvement 


\section{C-ARM picture of multilevel Lumbo-sacral fusion:-}

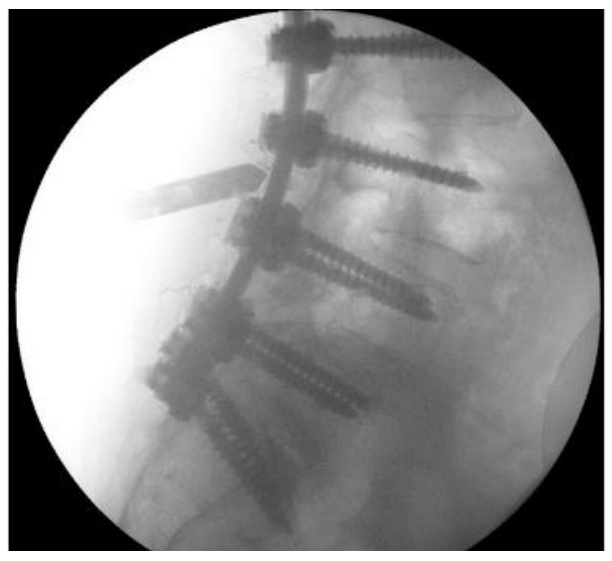

Physiotherapy for low back ache- Yoga for back ache:-

\section{Best Yoga Postures for Back Pain}

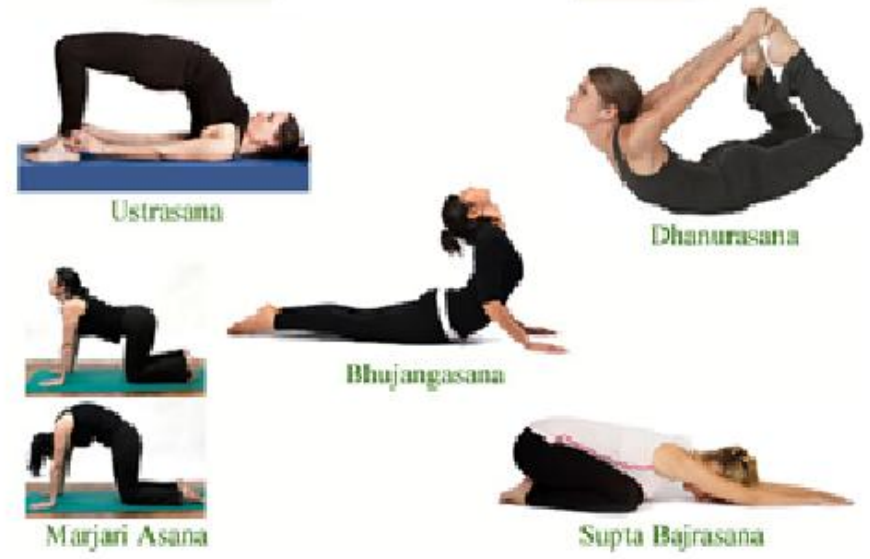

\section{Conclusion:-}

Low back ache has become a common ailment of $21^{\text {st }}$ century and with sedentary work conditions and lack of physical activities incidence is worsening. Most causes of low back ache can be treated conservatively $(90 \%)$ and only less than $10 \%$ require surgical intervention. It is a myth that surgery worsens neurological conditions. With the use of microscope, endoscope and minimal invasive procedures, spine surgery has become a sub-speciality by itself with success rate close to $95 \%$. Choosing properly indicated patients with good co-relation of clinical and radiological findings adds to good results in well trained hands. Surgery is an alternative only when conservative treatment fails to this common pathology. 